\title{
Electrooptic methods for measurement of small DC currents at high voltage level
}

\author{
Tønnesen, Ole; Beatty, Neville; Skilbreid, Asbjørn Ottar
}

Published in:

IEEE Transactions on Power Delivery

Link to article, DOI:

10.1109/61.32644

Publication date:

1989

Document Version

Publisher's PDF, also known as Version of record

Link back to DTU Orbit

Citation (APA):

Tønnesen, O., Beatty, N., \& Skilbreid, A. O. (1989). Electrooptic methods for measurement of small DC currents at high voltage level. IEEE Transactions on Power Delivery, 4(3), 1568-1572. https://doi.org/10.1109/61.32644

\section{General rights}

Copyright and moral rights for the publications made accessible in the public portal are retained by the authors and/or other copyright owners and it is a condition of accessing publications that users recognise and abide by the legal requirements associated with these rights.

- Users may download and print one copy of any publication from the public portal for the purpose of private study or research.

- You may not further distribute the material or use it for any profit-making activity or commercial gain

- You may freely distribute the URL identifying the publication in the public portal 
ELECTROOPTIC METHODS FOR MEASUREMENT OF SMALL DC CURRENIS AT HIGH VOLTAGE LEVEL
Ole Tonnesen
Neville Beatty
Ottar Skilbreid

Member IEEF

Electric Power Engineering Department, Build 325 Technical University of Denmark DK-2800 Lyngby

Keywords: Current Transducer, Pockels Cell, Optoelectronics.

Abstract.

Two electrooptic methods for measurement of DC currents at high voltage level, extending from the $\mathrm{nA}$ range and up to the milliampere range have been developed. First, by switching the polarity of a measured DC voltage across a Pockels cell, DC currents can be measured and transmitted along an optical fibre to an electrooptic converter. Second, by use of an electronic circuit the measured signal can be converted into a modulated frequency form for transmission along an optical fibre. These systems are described, measurement results are presented and improvements to be made in the future are outlined. The measuring methods can be used both for development and supervision of electrical insulating systems.

\section{Introduction}

Measurements of small DC currents at high voltage levels extending from the nA range and about six decades up to the milliampere range are of considerable interest both for development and supervision of electrical insulating systems. Leakage currents on for example outdoor insulators have been studied for many years [1] as they can yield valuable information about the flashover characteristics of the insulation systems. The increasing use of HVDC transmission systems has greatly emphasized the requirement of a deeper understanding of the behaviour in DC insulating sys tems. The development of electrooptic methods for the measurement of small DC-currents at high voltage levels has opened new ways for research in this area.

For this purpose, two different optical current transducer principles have been developed as presented in the following sections. One transducer contains a Pockels cell which modifies the light in a crystal according to the measured current or voltage. An analog signal is transmitted along an optical fibre to an electrooptic converter. The other transducer contains an

83 SM 641-3 A paper recommended and approved by the [EEE Power Systen Cominuications Cominttee of the [AFE ?ower Fingineering Society for presentation at the IREL/PES 1988 Suminer Mefting, Portland, Oregon, July $24-29,1988$. Manuscript subaitted February 1, 1988; nade available for printing May $18,1983$. electronic circuit for converting the current or voltage into modulated frequency form for transmission along an optical fibre.

DC vo1tage and current measurement using the Pockels Effect.

Pockels devices and their uses in the measurement of AC voltages have been described extensively, [2] [7], with the Pockels cell used being described in [7]. The Pockels cell used here is based on the electrooptic effect which occurs when an electrical field is applied to a $\mathrm{Bi}_{12} \mathrm{SiO}_{20}$ crystal.

The principle of the cell is shown in fig. 1 .

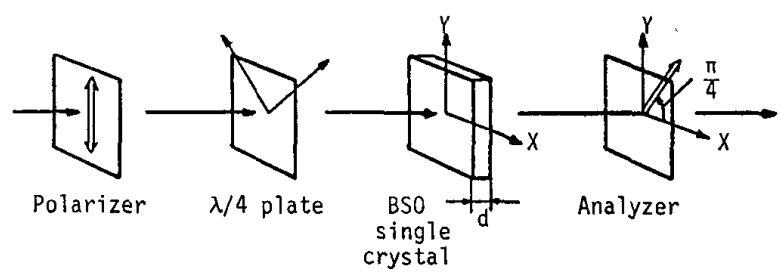

Fig. 1: Arrangement of the optical system.

Light of wavelength $0.85 \mu \mathrm{m}$ from a high-radiance LED is launched into a step-index multimode glass fibre (100 $\mu \mathrm{m}$ core). At the cell the light passes through a polarizer and a $\lambda / 4$ plate and thus becomes circularly polarized. Dependent on the voltage applied to the $\mathrm{Bi}_{12} \mathrm{SiO}_{20}$ crystal, this circularly polarized light then is changed to eliptically polarized light due to the birefringence of the crystal. This phase modulation is finally converted to amplitude modulated light by an analyser. The modulated light is then send back to an electrooptic converter via a second fibre. The light detector is a PIN photo diode.

The principle of the amplitude modulation is shown in $\mathrm{fig} .2$.

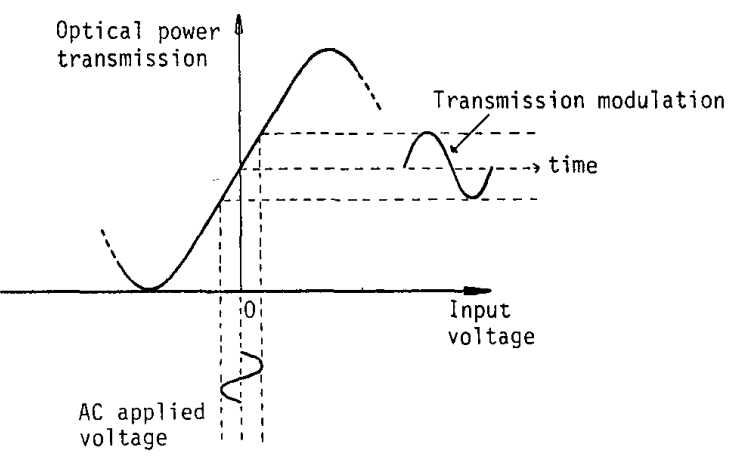

Fig. 2. Amplitude modulation principle: Optical power transmission of 1 ight which emerges from the sensor versus input voltage. Also shown is the applied AC voltage versus the modulated optical power output.

0885-8977/89/0700-1568\$01.00(C) 1989 IEEE 
If an $A C$ voltage is applied to the cell, the output light power will consist of an AC component overlaid on a DC component as shown in fig. 2 .'

The $A C / D C$ ratio $m$ is given $[10$ ] by

$$
m=\pi \frac{V(t)}{V_{\pi}} \cdot f(V(t))
$$

where

$$
f(V(t))=\frac{\sin \left[\left(\pi \frac{V(t)}{V_{\pi}}\right)^{2}+(2 \theta \cdot d)^{2}\right]^{1 / 2}}{\left[\left(\pi \frac{V(t)}{V_{\pi}}\right)^{2}+(2 \theta \cdot d)^{2}\right]^{1 / 2}}
$$

$\mathrm{V}(\mathrm{t})$ the input voltage signal, $\mathrm{V}_{\pi}$ the half wave voltage $6800 \mathrm{~V}, \theta=10.5 \% / \mathrm{mm}$ is the optical activity of the crystal for light of wave length $870 \mathrm{~nm}$ and $d$ the thickness of the crystal (approx. $5 \mathrm{~mm}$ ).

The cell is designed for long time exposure of voltages up to $500 \mathrm{~V}_{\text {rms }}$, and for voltages in this range $f(V(t))$ varies between 0.5738 and 0.5673 i.e. $f(V(t)) \simeq$ a constant.

Thus the modulation ratio m varies linearly with the input voltage signal $V(t)$, i.e. a sine voltage applied to the cell will yield an analog light power output with a sine component overlaid on a DC component.

The block diagram for the measuring system is shown in fig. 3. The circuit compensates for the optical losses which occur in the optical fibres connectors and sensors, by mean of a negative feedback loop.

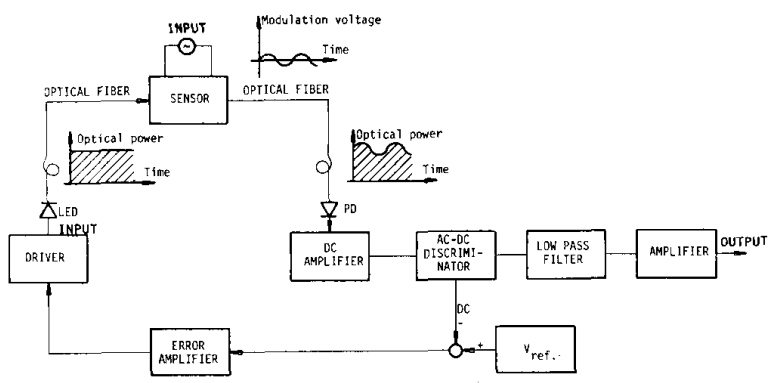

Fig. 3. Block diagram of the measuring system.

For DC measurements we have developed a system wherein the voltage is applied(across the Pockels cell) not directly but via an electrooptic circuit. This circuit periodically inverts the polarity of the voltage across the cell, effectively applying a square wave voltage with amplitude equal to the DC voltage to be measured - the main reasons for the necessity of its inclusion are outlined below.

1. Clearly, a1though polarization modulation is the mechanism whereby Pockels sensors function, it is amplitude modulation which is actually observed and the sensors will be sensitive to optical power losses other than the voltage induced intensity modulation in the Pockels cell. Therefore some form of intensity referencing is required for stable long term sensor operation. There is no problem when measuring AC signals as the DC level in the detected light signal can be used as a reference but this could not be done if a DC voltage was applied directly to the Pockels cell as the reference and signal would not be separable.

2. Furthermore, the response of the Pockels cell to a step voltage is not, as expected from Figure 1, a step change in transmission. There is an initial jump (or fall) in transmission proportional to the height of the step voltage but this is then followed by a decay towards the initial transmission which has a time constant of about one second. This effect is thought to be due to polarizations, which change the rotary power of the BSO crystal, being induced by a "long term" DC field. A clear consequence is that transmission through the Pockels cell will not be stable measure of a DC voltage applied across the cell.

The switching circuit Figure 4 is based around two high voltage transistors $\mathrm{T}_{\mathrm{A}}, \mathrm{T}_{\mathrm{B}}$, with the Pockels cell electrodes being each connected to one of the transis. tor collectors. The transistor collectors are connected via resistors $R_{A}$ and $R_{B}$ to the positive side of the voltage to be measured and the emitters to the negative side. The currents flowing into the bases of the transistors are independently controlled by the light levels following on the two photodiodes $P D_{A}, P D_{B}$. The resistors $R_{A}$ and $R_{B}$ are relatively large ranging from 1

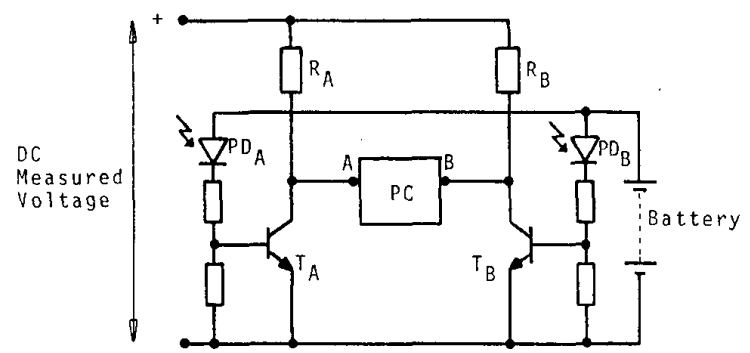

Fig. 4: Switching circuit. The voltage across the Pockels cell PC is periodically inverted.

to $10 \mathrm{M} \Omega$ but the impedence of the Pockels cell is much larger (hundreds of $M \Omega$ ) so the voltages at the Pockels cell electrodes can be controlled independently by varying the light levels on the photodiodes. The switching operation of the circuit can be explained by looking at the voltage across the Pockels cell when one photodiode $\mathrm{PD}_{\mathrm{A}}$ is in darkness and the other $\mathrm{PD}_{\mathrm{B}}$ is illuminated with say $300 \mu \mathrm{W}$, with the voltage to be measured being $300 \mathrm{~V}$. The current flowing into the base of transistor A will only be the dark photodiode current of the order of $10 \mathrm{nA}$ and the transistor will not conduct significantly. The voltage at electrode $A$ of the Pockels cell will be effectively $300 \mathrm{~V}$. The current flowing into the base of transistor $B$ will be of the order of $150 \mu \mathrm{A}$ (photodiode sensitivity is $0.5 \mathrm{~A} / \mathrm{W}$ ). With a transistor current gain of 5 and load resistor $R_{B}$ of 1 Megaohm this current is easily enough to saturate the transistor producing a voltage at electrode $B$ of the Pockels cell within a few hundred millivolts of the negative side of the DC voltage to be measured. Therefore in this case there will be a voltage induced across the Pockels cell with a magnitude within a few hundred millivolts of the voltage to be measured, electrode $A$ being positive with respect to electrode $B$. Clearly if the situation is reversed and $\mathrm{PD}_{\mathrm{A}}$ is illuminated while $P D_{B}$ is not then the polarity of the voltage across the Pockels cell will also be reversed.

In the system block diagram Figure 5 it can be seen that the photodiodes are illuminated by light carried from two Light Emitting Diodes at ground potential via two separate optical fibres. The LEDs are square wave current modulated so as to be periodically switched on and off and are in mutual antiphase i.e. while one LED is emitting the other is not. The fibre used is relatively large having a core diameter of 600 microns, so that using standard LEDs 300 microwatts or more can easily be transmitted to the photodiodes. 


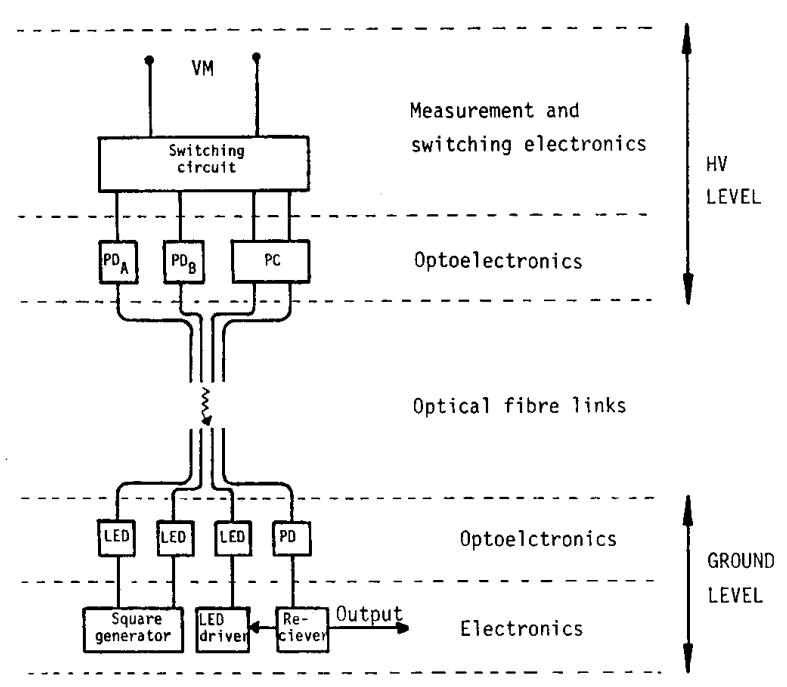

Fig. 5: Block diagram of the optical current transducer.

As we have now generated an $A C$ voltage across the Pockels cell the other side of the measurement system is the same as would be used if we were actually measuring AC voltages. Unmodulated light is launched from an LED into an optical fibre and carried to the Pockels cell. On passing through the Pockels cell the intensity is modulated with a square wave whose amplitude is proportional to the DC voltage to be measured. The modulated light is carried by a second optical fibre to a receiver at ground level.

\section{System performance - Range, Linearity, Resolution.}

In this section the potential system performance will be assessed with reference to the results of a preliminary test, shown in Figure 6 . The graph shows the amplitude of the sensor output squarewave (read from an oscilloscope) versus the DC voltage applied across the sensor (read from a high accuracy digital voltmeter) as the applied voltage was varied between $400 \mathrm{mV}$ and $300 \mathrm{~V}$.

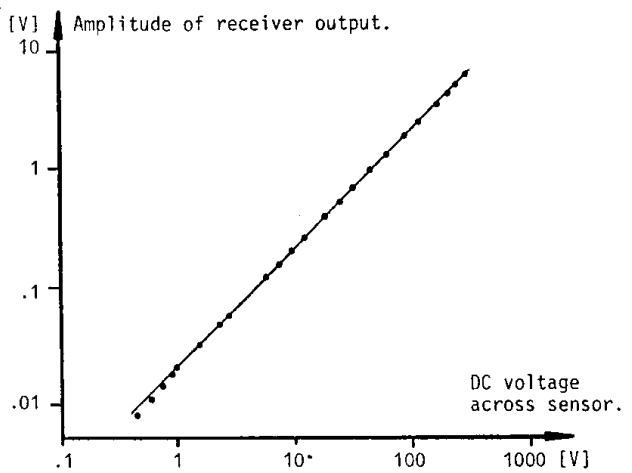

Fig. 6: Amplitude of receiver output square wave versus DC voltage applied across the sensor.

The most noticeable feature of the graph is that from the maximum applied voltage down to about $1 \mathrm{~V}$ it is linear with slight nonlinearity being observed in the range from $1 \mathrm{~V}$ to $400 \mathrm{mV}$. This nonlinearity is due to the emitter-collector voltages becoming comparable to the applied voltage. Also in this region noise becomes significant (receiver shot and Johnson noise combined are about $3 \mathrm{mV}$ RMS) so the lower limit on the voltage that can be measured is about $0.5 \mathrm{~V}$. At the up- per end of the range results were only taken up to an applied voltage of $300 \mathrm{~V}$ as this was the withstand limit of the transistors used.Transistors are available which will withstand $1 \mathrm{kV}$ or more and thus the measurement range can easily be extended up to $500 \mathrm{~V}$, which is within the maximum level of the Pockels cell.

The sensor can measure currents if connected across a resistor through which they flow. For linear operation the series resistance $R_{S}$ should probably be an order of magnitude less than the resistors $R_{A}, R_{B}$. The minimum measurable current would be that which produces a $0.5 \mathrm{~V}$ drop across $R_{S}$ and if for example $R_{S}$ was $100 \mathrm{k} \Omega\left(R_{A}=R_{B}=1 \mathrm{M} \Omega\right)$ the minimum measurable current would be $5 \mu \mathrm{A}$. If smaller currents were to be measure $R_{S}, R_{A}, R_{B}$ would have to be increased.Raising resistors $R_{A}$ and $R_{B}$ will have two effects - firstly the switching time will be increased as this is determined by $R_{A}, R_{B}$ and the capacitances of the photodiodes $P D_{A}, P D_{B}$. This would lead to an output which is not a proper square wave, but as an exact square wave is not essential to operation (we are only interested in transmission changes when the polarity is inverted)this effect would not cause the lower limit for current measurement. If $R_{A}$ and $R_{B}$ are raised to about $10 \mathrm{M} \Omega$ then there will be a voltage drop across them of about $0.5 \mathrm{~V}$ due to the photodiode "dark currents". This sets the upper limit of $R_{A}, R_{B}$ at about $10 \mathrm{M} \Omega$ and hence the upper limit for $R_{S}$ at about $1 \mathrm{M} \Omega$. This in turn sets the lower limit for the current to be measured at around $0.5 \mu \mathrm{A}$.

\section{Current to frequency transducer}

An alternative current measuring device using a unijunction transistor has been developed and tested. A unijunction transistor,UJT, is a three terminal device, constructed as a n-type silicon resistor with ohmic contacts at both ends. An emitter rectifier contact $E$ is inserted between the two ohmic contacts, which here are called $B 1$ and $B 2$. Under normal operation, $V_{B B}$, the voltage of $B 2$ relative to $B 1$, is positive. Now, when a voltage equal to $n \cdot V_{B B}$ relative to $B 1$ is applied to the emitter $E$, a current will start to flow. The factor $n$ will typically be in the range $0.50-0.75$. Once the current starts to flow an avalanche process turns the $E$ - Bl region into a highly conducting path with a negative resistance characteristic. Therefore, a current pulse train with a frequency dependent upon the applied voltage, is established. The UJT component has a very stable trigger voltage and good temperature stability.

The diagram of the current transducer is shown in Figure 7 .

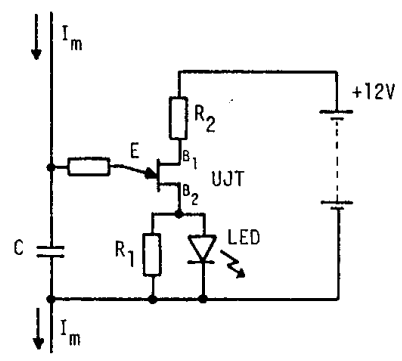

Fig. 7: Current to frequency transducer. UJT: Unit junction transistor, C: Discharging capacitor, $I_{m}$ : Current to be measured.

The voltage at which the capacitor will be discharged is proportional to the auxiliary supply voltage to the UJT, and thus, the stability of the supply voltage will determine the accuracy of the current measurement. The capacitor discharge currents are passed through a LED and the light pulses (approx. $1 \mu \mathrm{sec}$. duration) are 
transmitted via an optical fibre to a reciever, where the pulses are counted.

The calibration curve for the transducer in Figure 7 is shown in Figure 8 . The pulse frequency versus the DC current is linear within the accuracy ( \pm 18 ) of the measuring instruments used.

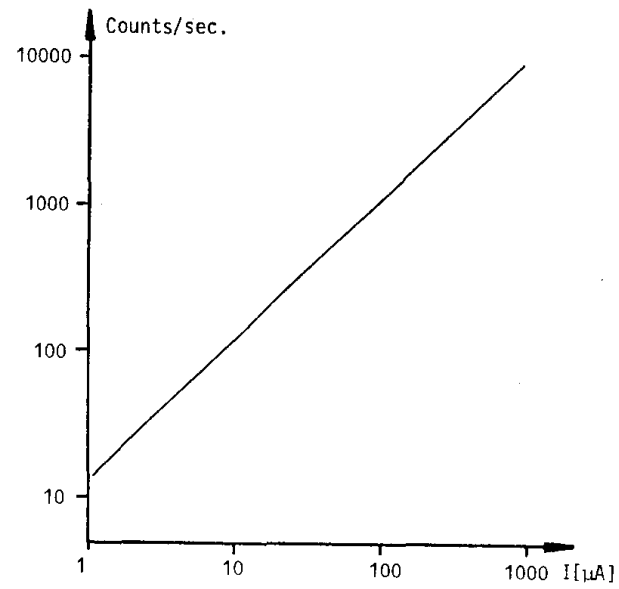

Fig. 8: Calibration curve for the current transducer. Pulse frequency versus measured DC current.

For example, at a current level of $1 \mathrm{~mA}$, the pulse frequency is approximately $10^{4}$ pulses per second, and a resolution of \pm 18 is obtained within $10^{-2}$ seconds. However, at $10 \mu \mathrm{A}$ level a measuring time of 1 second is necessary to obtain the same resolution.

Instead of just counting the discharge pulses, they can be used as timing pulses for a high frequency counter operating at e.g.10 Megacycles per second, and thus the number of counts are inversely proportional to the measured current. In Figure 9 a modified circuit for measuring higher DC current levels is presented.

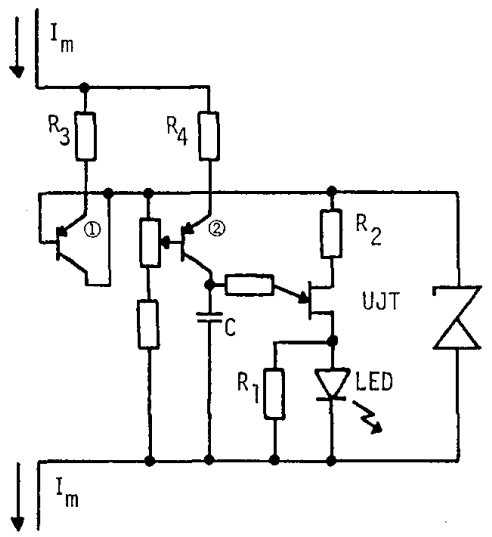

Fig. 9: Modified current to frequency transducer, without auxiliary power supply; the bypass current through transistor 1 is passed through a parallell zener diode voltage regulator.

The bypass current through transistor No 1 is led through a parallel voltage regulator (e.g. a Zener diod e), which supplies the voltage to the UJT. The lower limit of the current that now can be measured is determined by the minimum current needed to activate the UJT. The ratio between the current bypassed by transistor No 1 and the corresponding current through transistor No 2 (which charges the capacitor) will very closely be equal to the inverse ratio of the emitter resistances $R_{3}$ and $R_{4}$. However, the transducer circuit in Figure 7 does not have the same wide dynamic range as the circuit in Figure 5 , as the base emitter voltages of the two transistors will not cancel each other completely when the transistor currents are of different magnitude.

\section{Discussion and conclusions.}

For long term operation inclusion of a battery in either of the measurement methods described here is not desirable.

With the Pockels device system there is a requirement for the power supply to generate only about $100 \mu \mathrm{A}$ and enough voltage to reverse bias the photodiodes (a few Volts), so the power requirement is less than $0.5 \mathrm{~mW}$. This could be generated by sending optical power up to the high voltage level or if the current to be measured was larger then a few milliamperes some would be drawn off to power a Zener diode. Systems are now under deve1opment in which the polarity inversion would be performed by a bridge arrangement of optoelectronic components (e.g. high voltage photodiodes) and which would not require an auxiliary power supply.

During the preliminary test the polarity inversion was at a frequency of $250 \mathrm{~Hz}$ and the signal to noise ration for $300 \mathrm{~V} \mathrm{DC}$ input was greater than $60 \mathrm{~dB}$. In a measurement situation the output square wave would probably be rectified and low pass filtered to give a DC output. If the desired system response was, $10 \mathrm{~Hz}$ then a signal to noise ratio of $70 \mathrm{~dB}$ would be achievable.

Regarding the current to frequency transducer the current range which can be measured by the circuit in Figure 5 extends over about four orders of magnitude. The lower current limit is determined by the emitter current of the order $0.1 \mu \mathrm{A}$, required to bring the UJT into the negative resistance region.

However, by applying short negative voltage pulses of approx. $0.75 \mathrm{~V}$ (generated by a second unijunction relaxation oscillator) to the base B2, the lower current limit can be reduced to about $1 \mathrm{nA}$. The upper limit of the measured current is about $1 \mathrm{~mA}$ at which the emitter $\mathrm{E}$ to base $\mathrm{B} 1$ resistance changes from the negative to the positive region.

In conclusion we can say that two alternative transducer systems for measuring small DC currents at high voltage levels have been developed.

The transducer using the Pockels effect can mea. sure DC currents with a lower 1 imit around $0.5 \mu \mathrm{A}$. The upper limit is given by the choice of the measuring resistance.

The current to frequency transducer can measure currents in the range $1 \mathrm{nA}-1 \mathrm{~mA}$.

The development of the transducer systems is still in progress. 
References Flashover" ELEKTRA No 78 , Oct. 1981.

R.E. Hebner,R.A. Malewski,E.C. Cassidy, "Optical methods of Electrical Measurement at High Voltage Levels"

Proceedings of the IEEE, Vol. 65, No 11 , November 1977.

B.E. Jones, "Optical Fibre Sensors and Systems for Industry".

J. Phys E: Sci. Instrum., Vol. 18, 1985.

[4] Y. Aoshima, T. Harada, "Voltage Distribution Characteristics of Polluted Insulators" Fourth International Symposium on High Voltage Engineering, paper No. 62.06. Athens, Greece, September 1983.

M. Kanoi, et.al. "Optical Voltage and Current Measuring System for Electric Power Systems". IEEE Trans. on Power Delivery, Vol. PWRD-1, No 1 , January 1986 .

[6] S. Ihara, "BSO/Fiber-optic Voltmeter". Denshi Tokyo(IEEE Tokyo Section), No 21, 1982, pp $102-105$

[7] T. Mitsui, K. Hosoe, H. Usami, S. Miyamoto, "Development of Fiber-Optic Voltage Sensors and Magnetic-Field Sensors" IEEE 86 SM $442-8$. 0le Tønnesen was born in Virum, Denmark on August the 26, 1943. He received a M.Sc. degree in 1969 and a Ph.D. degree in 1973 in electrical engineering from the Electric Power Engineering Department, the Technical University of Denmark. From 1973 - 75 he worked with R\&D at the company Thrige-Titan A/S, from 1975 . 85 he worked with R\&D ASEA RESEARCH AND INNOVATION in Sweden. From 1985 he holds the rank of Professor of Experimental High Voltage Technique at the Electric Power Engineering Department, Technical University of Denmark. Ole Tønnesen is a member of IEEE.

Neville Beatty was born in Banbridge, Northern Ireland on May the 26, 1961 and received the B.Sc. degree in 1983 and M.Sc.degree in 1984 in applied optics at the Imperial College of Science and Technology, London. 1985-87 he worked with industrial R\&D at the Department of Electronic and Electrical Engineering, University College London. From 1987-88 he worked with R\&D at the Electric Power Engineering Department, Technical University of Denmark.

Ottar Skilbreid was born in Western Norway August 5 , 1928. In 1953 he mooved to Denmark where he in 1956 received a B.Sc. in electronics engineering. From 1956-1967 he worked in experimental Nuclear Physics at the Niels Bohr Institute, Denmark, Argonne Nationale Laboratories IIl, U.S.A., the University of Princeton, N.J., U.S.A., and for a shorter period of time at the National Bureau of Standards, M.Y.,U.S.A. In 1967 O.Skilbreid joined as R\&D manager, the Danish company Danfysik, who's main activity is production of customs designed instruments and equipment for Physics Research Laboratories. In 1978 0. Skilbreid joined the Electric Power Engineering Department, Technical University of Denmark where he is working with $R \& D$.

\section{Discussion}

Harold Kirkham and Alan Johnston (Jet Propulsion Laboratory, Pasadena, CA): We would like to congratulate the authors on describing two useful-looking devices. We share with the authors the feeling that inexpensive and moderately accurate optical measurement systems have wide application possibilities in laboratory and field measurements. The wide dynamic range of the instruments described in this paper should make them extremely useful, and their simplicity should make them readily producible.

Our question relates to the suitability of materials such as the BSO used in the Pockels device for the high voltage environment. No doubt the author of this paper are aware that another worker, also in Scandinavia, has been using a Pockels probe as a way to measure dc electric fields near high voltage bushings. It has been reported that one of his field meters was involved in a flashover from the bushing, at which time the Pockels crysta was destroyed. This particular application used a rotating enclosure for the Pockels cell, so that there is a possibility that the destruction of the crystal was due to a failure in the mechanical construction used. It seems more likely, however, that the destructive energy had its origins in the flashove itself. While flashovers may not be commonplace in the real world of power systems, they are not unknown, and smaller corona activity certainly should be regarded as routine. Have the authors any observations on the suitability of high impedance, fragile optical materials such as BSO for application in real-world, outdoor power system measurements?

Manuscript received August 22, 1988.

\section{OLE TØNNESEN}

The authors would like to thank the discussers for their interest in this paper and for their insightful question.

Materials such as BSO have been used with good experience for measurement of voltage or electric field in high voltage environment. However, to the best of our knowledge, the long term behaviour of such measuring systems has not yet been reported. The potential applications can be divided into two main groups: 1) long term field service applications and 2) research and development applications.

Now, for both groups, the measuring device should be supplied with an overvoltage protection (approx. $1000 \mathrm{~V}$ in our case) to prevent short time electrical breakdown of the Pockels device.

Furthermore, the measuring device should be designed in such a way, that the occurrence of corona under service conditions is eliminated either - if possible - by prober shielding or by constraining the magnitude of the electric field around the measuring device to a maximum level.

However, dealing with experimental research and development work, one may unforseenly exceed these limits, and as a concequence deteriorating partial discharges or striking plasma channels may destroy the measuring device. Thus, by choosing the right design of the measuring device with regard to the high voltage environment, it is considered that the technique is suitable for outdoor power system measurements. A further question may concern the long term resistance of such a measuring device against mechanical, thermal and chemical aging under service conditions. The years to come may give an answer to that.

Manuscript received September 29, 1988. 